\title{
TANTANGAN BISNIS IKAN HIAS TIGER CATFISH (Pseudoplatystoma fasciatum) MELALUI PENGUASAAN TEKNOLOGI PEMIJAHAN
}

\author{
Eni Kusrini, Agus Priyadi, dan Anjang Bangun Prasetio \\ Balai Penelitian dan Pengembangan Budidaya Ikan Hias \\ Jl. Perikanan No. 13 Pancoran Mas, Depok 16436 \\ E-mail: publikasi.bppbih@gmail.com
}

\begin{abstract}
ABSTRAK
Ikan tiger catfish (Pseudoplatystoma fasciatum) merupakan salah satu ikan hias hasil introduksi yang berasal dari Sungai Amazon Amerika Latin dan mempunyai nilai ekonomi yang cukup tinggi terutama untuk komoditas ekspor. Tujuan dari penelitian ini adalah untuk memberikan informasi tentang pembenihan ikan tiger catfish secara buatan. Metode yang digunakan untuk pemijahan buatan ikan tiger catfish ini adalah dengan stimulasi hormon gonadotropin. Calon induk ikan hias tiger catfish dapat matang gonad dipelihara dalam kolam beton berukuran $2,5 \mathrm{~m} \times 2,0 \mathrm{~m} \times 0,8 \mathrm{~m}$ dengan ke dalaman air antara 50-60 cm dilengkapi dengan sistem sirkulasi. Perbandingan antara jantan dan betina yaitu 1:2. Bobot rata-rata induk yang siap dipijahkan sekitar 2,5 kg dan sudah berumur minimal dua tahun. Jumlah telur yang dihasilkan setiap satu induk dapat mencapai 300.000 butir dengan daya tetas rata-rata $80 \%$. Telur akan menetas semua dalam waktu $15-19$ jam pada suhu berkisar antara $26^{\circ} \mathrm{C}-30^{\circ} \mathrm{C}$. Larva yang telah menetas tetap dibiarkan dalam akuarium sampai kuning telur yang menempel di tubuh habis termakan. Keberhasilan pembenihan diawali dari pengelolaan induk yang benar untuk dapat matang gonad, sehingga kualitas telur bagus dan akan menghasikan benih-benih yang berkualitas. Teknik pembenihan juga menjadi faktor yang menentukan untuk keberhasilan pembenihan. Teknologi pemijahan buatan dengan menggunakan stimulasi hormon gonadotropin ikan tiger catfish telah dikuasai dan telah berkembang di para breeder ikan hias.
\end{abstract}

KATA KUNCI: $\quad$ tiger catfish, pemijahan buatan, stimulasi hormon

ABSTRACT: Business challenge tiger Catfish (Pseudoplatystoma fasciatum) through controlled spawning technology. By: Eni Kusrini, Agus Priyadi, and Anjang Bangun Prasetio

Tiger catfish (Pseudoplatystoma fasciatum) is one the introduction of ornamental fish from Latin America and the Amazon River has a high economic value, especially for export commodities. The purpose provide information about the tiger catfish by artificial spawning. The method used for artificial spawning tiger catfish is the hormone gonadotropin stimulation. Brood fish can mature gonads tiger catfish reared in concrete ponds measuring $2.5 \times 2.0 \times 0.8 \mathrm{M} 3$ with water depths between 50-60 $\mathrm{cm}$ is equipped with a circulation system. Comparison between male and female is 1: 2. Average weight ready spawn about $2.5 \mathrm{~kg}$ and at least 2 years old. The number of eggs produced 300,000 grains with haching rate 80\%. All the eggs will hatch within 15-19 hours at temperatures ranging from $260 \mathrm{C}-30 \mathrm{oC}$. Larvae reared in the aquarium. The success breed of broodstock management. Breeding technique is also a decisive factor for the success of the hatchery. Artificial spawning technologies use the gonadotropin hormone stimulation tiger catfish have been mastered and has grown in the ornamental fish breeders.

KEYWORDS: $\quad$ Pseudoplatystoma fasciatum, artificial spawning, hormone stimulated

\section{PENDAHULUAN}

Ikan tiger catfish (Pseudoplatystoma fasciatum) merupakan salah satu ikan hias hasil introduksi yang berasal dari Sungai Amazon Amerika Latin dan mempunyai nilai ekonomi yang cukup tinggi terutama untuk komoditas ekspor. Informasi yang didapatkan di lapangan atau ekspotir ikan hias di Jakarta dan Jawa Barat (Bogor, Depok, Tangerang, Bekasi) menunjukkan bahwa ikan hias tiger catfish masuk ke Indonesia sekitar tahun 1990 untuk dipelihahara dan dijual kembali. Setelah kurun waktu kurang lebih lima tahun berikutnya ikan hias jenis catfish ini akhirnya berhasil dipijahkan oleh para breeder atau hobiis melalui metode induced breeding (pemijahan buatan), namun belum memberikan hasil yang maksimal sehingga masih memberi tantangan untuk terus dicoba. Setelah pembiakan dilakukan secara terus-menerus akhirnya pada saat ini telah dikuasai teknologi pembenihannya secara optimal, meskipun dalam berjalannya waktu masih banyak kendala yang ditemui di antaranya teknik pematangan gonad, pemijahan alami yang belum dapat 


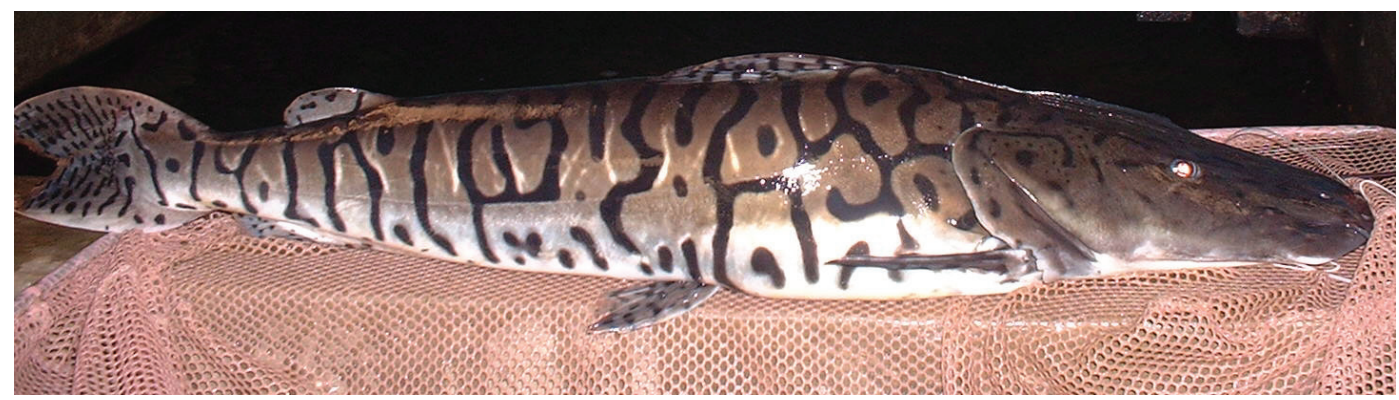

Gambar 1. Induk ikan hias Tiger Catfish (Pseudoplatystoma fasciatum)

Figure 1. Brood of tiger catfish (Pseudoplatystoma fasciatum)

dilakukan, dan perawatan larva. Penelitian-penelitian skala laboratorium untuk pemecahan masalah-masalah pada budidaya ikan hias tigerfish ini belum banyak dilakukan.

Ikan hias tiger catfish mempunyi nama lain tiger shovelnose catfish mempunyai bentuk badan yang mirip seperti ikan patin atau pangasius. Badannya bergarisgaris vertikal berwarna hitam yang berhubungan membentuk huruf " $Y$ " di bagian punggung, bahkan kadang-kadang ada bintik hitam yang agak tebal di bagian ventral sehingga seluruh tubuh ikan bercorak loreng-loreng (Gambar 1).

Panjang total ikan betina yang matang gonad mempunyai panjang lebih dari $50 \mathrm{~cm}$ sedangkan pada induk ikan jantan $45 \mathrm{~cm}$ dengan berumur telah mencapai sekitar dua tahun. Menurut Le Bail et al (2000), panjang total induk dapat mencapai $104 \mathrm{~cm}$ atau 41 inci dengan bobot sekitar $70 \mathrm{~kg}$. Ciri utama secara fenotipe adalah badan memiliki sirip caudal bercabang dua, berwarna keabu-abuan di sepanjang sisi tubuh, dan warna coklat keabu-abuan menutupi punggung pada bagian dorsal. Badan bagian bawah berwarna krem putih dan terdapat garis berwarna hitam gelap secara vertical dan siripnya terdapat bintik-bintik hitam (Sands \& David, 2006).

Menurut Eschmeyer (2005), ikan hias tiger catfish mempunyai karakteristik yang mirip dengan ikan patin, namun secara klasifikasi berbeda. Sedangkan klasifikasi dari ikan hias tiger catfish adalah sebagai berikut:

$\begin{array}{ll}\text { Kingdom } & \text { : Animalia } \\ \text { Phylum } & \text { : Chordata } \\ \text { Sub Phylum } & \text { : Vertebrata } \\ \text { Class } & \text { : Actinopterygii } \\ \text { Sub Class } & : \text { Neopterygii } \\ \text { Infra Class } & : \text { Teleostei } \\ \text { Super Ordo } & \text { : Ostariophysi } \\ \text { Ordo } & \text { : Siluriformes } \\ \text { Family } & : \text { Pimelodidae } \\ \text { Genus } & : \text { Pseudoplatystoma } \\ \text { Spesies } & : \text { Pseudoplatystoma fasciatum (Linnaeus, } \\ & \text { 1766) }\end{array}$

Ikan hias tiger catfish berasal dari Amerika Latin yang dialiri oleh Sungai Amazon yaitu Bolivia, Argentina,
Brazil). Sungai Amazon merupakan habitat asli ikan jenis catfish ini, yang memiliki kedalaman sekitar 5 $\mathrm{m}$, dengan $\mathrm{pH} 6,5-7,8$ suhu air berkisar antara $23^{\circ} \mathrm{C}$ $28^{\circ} \mathrm{C}$, kadar nitrat di bawah $200 \mathrm{mg} / \mathrm{L}$, dan kandungan ammonia maksimal 5 mg/L (Teddy, 2006).

Ikan hias tiger catfish merupakan ikan demersal yang lebih menyukai dasar perairan dan akan muncul di permukaan apabila mencari makan. Ikan hias ini bersifat karnivora dan kecenderungan berperilaku kanibalisme yang tinggi terutama saat berukuran benih. Menurut Teddy (2006), ikan ini lebih menyukai memangsa jenis-jenis ikan kecil dan hewan kecil lainnya seperti ikan guppy, goldfish, cacing tanah, udang-udang kecil, dan lain-lain. Pada lingkungan pemeliharaan ikan hias tiger catfish dapat diberi makan ikan kecil hidup maupun mati, ikan rucah, mujair, atau cacahan daging siput, cacing tanah, selain dapat juga diselingi (dilatih) dengan pakan buatan.

Tujuan dari penelitian ini adalah untuk memberikan informasi tentang pembenihan ikan tiger catfish secara buatan. Sebagai ikan hias introduksi ikan tiger catfish belum dapat memijah secara alami dalam lingkungan yang terkontrol.

\section{BAHAN DAN METODE}

Calon induk ikan hias tiger catfish dapat matang gonad dipelihara dalam kolam beton berukuran 2,5 m x 2,0 m x 0,8 m dengan kedalaman air antara 50-60 $\mathrm{cm}$ dilengkapi dengan sistem sirkulasi. Untuk menjaga kualitas air agar tetap bagus dilakukan penyiponan apabila air terlihat kotor dan penggantian air setiap minggu sebanyak 30\%. Kandungan oksigen terlarut dikondisikan lebih dari $3 \mathrm{mg} / \mathrm{L}$, pH 6,5-7,5 suhu air antara $26^{\circ} \mathrm{C}-30^{\circ} \mathrm{C}$ dan bebas dari cemaran.

Pakan yang diberikan untuk memacu kematangan gonad dianjurkan berupa ikan hidup atau bisa juga ikan yang sudah mati namun masih segar. Pada lingkungan budidaya pakan yang diberikan berupa ikan selar, udang kecil, cacing tanah, dan ikan cumi. Pakan yang diberikan sebanyak 3\%-5\% dari bobot induk, sedangkan frekuensi pemberian pakan dua kali sehari.

Pengelolaan calon induk yang telah diketahui umurnya dipelihara dalam kolam beton berukuran bak 2,5 m x 2 m x 0.8 m dengan kepadatan sebanyak 


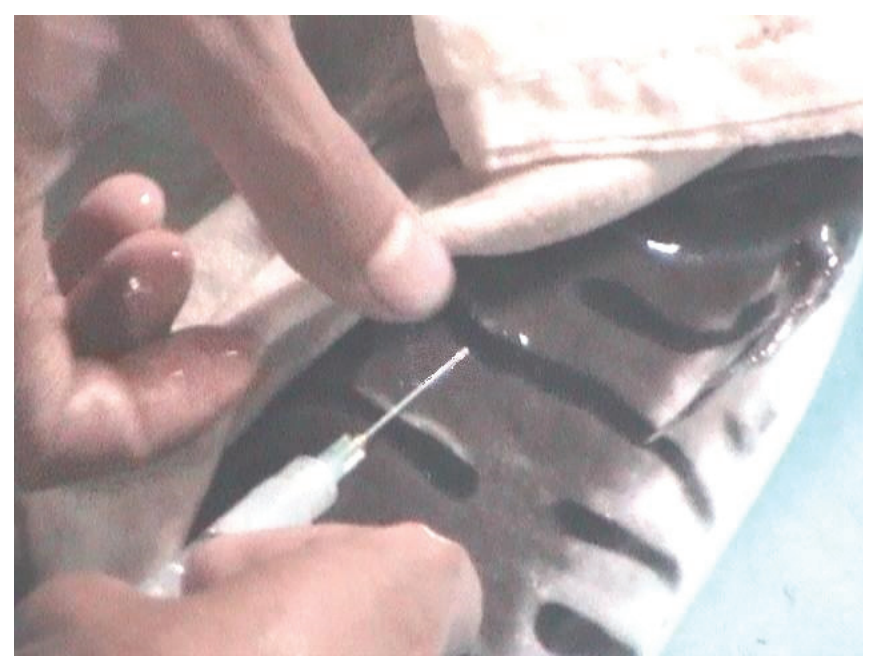

Gambar 2. Penyuntikan induk dengan menggunakan hormon gonadotropin

Figure 2. Fish injection used gonadotrophin hormone

6-8 ekor. Perbandingan antara jantan dan betina yaitu $1: 2$. Bobot rata-rata induk yang siap dipijahkan sekitar $2,5 \mathrm{~kg}$ dan sudah berumur minimal dua tahun. Induk jantan biasanya akan lebih cepat matang gonad dari pada induk betina. Ciri-ciri induk betina yang telah matang gonad antara lain:

1. Perut terlihat membuncit dan apabila diraba terasa halus den lembek

2. Alat genital berwarna merah jambu dan kalau ditekan sedikit akan menonjol

3. Diameter telur $>1 \mathrm{~mm}$ dan bulat

4. Warna telur kuning cerah dan bening

\section{HASIL DAN BAHASAN}

Keberhasilan budidaya ikan sangat tergantung dengan keberhasilan sistem pemijahan. Pemijahan ikan hias tiger catfish sampai saat ini masih dilakukan secara buatan yaitu dengan stimulasi hormon gonadotropin atau induced spawning. Induced spawning tersebut pada umumnya dilakukan terhadap jenis ikan yang tidak dapat memijah secara alami (Hardjamulia \& Atmawinata, 1990; Gaffar \& Muflikhah, 1992; Hardjamulia et al., 1992). Jenis hormon yang banyak digunakan oleh para breeder ikan hias tiger catfish selama ini yaitu hormon komersial yang telah banyak dijual merk @ovaparim. Hormon gonadotropin yang lain yaitu kelenjar hipofisa yang diekstraksi dari ikan mas juga dapat digunakan.

Penggunaan hormon dianjurkan sesuai dengan dosis yaitu untuk induk betina sebanyak $0,5-0,7 \mathrm{~mL}$ per $\mathrm{kg}$ bobot tubuh atau dengan ekstrak kelenjar hipofisa ikan mas sebanyak $3 \mathrm{~mL}$ per $\mathrm{kg}$ bobot badan. Sedangkan untuk induk jantan menggunakan dosis sebesar 0,3$0,5 \mathrm{~mL}$ per $\mathrm{kg}$ bobot badan. Penyuntikan dilakukan pada bagian sirip punggung secara intramuscular. Protokol penyuntikan induk betina dapat dilakukan satu kali atau dapat juga dilakukan sebanyak dua kali tergantung pada kondisi kematangan gonad. Apabila dilakukan penyutikan satu kali dosis hormon yang digunakan sekaligus disuntikkan dan tinggal menunggu rentang waktu 8-12 jam untuk dilakukan striping, namun apabila penyuntikan dilakukan dua kali, pada penyuntikan pertama sebanyak $30 \%$, kemudian setelah masa laten 8-12 jam dilakukan penyuntikan kedua sebanyak 70\%. Penyuntikan dua kali dilakukan apabila kondisi telur belum maksimal sehingga masih agak sulit untuk diovulasi. Keragaan penyuntikan induk dengan menggunakan hormon gonadotropin disajikan pada Gambar 2.

Selain teknik pemijahan, lingkungan yang sesuai juga sangat menentukan keberhasilan pembenihan, dalam hal ini adalah suhu air yang stabil. Suhu sangat besar pengaruhnya terhadap kerja hormonal. Kisaran suhu antara $28^{\circ} \mathrm{C}-30^{\circ} \mathrm{C}$ selama waktu $13-19$ jam pasca penyuntikan.

Pembuahan kering dilakukan di luar dengan cara mengeluarkan telur maupun sperma (stripping/ pengurutan). Secara visual tanda-tanda ikan akan ovulasi yaitu gerakkan ikan lambat, kelihatan gelisah, naik turun ke permukaan air, dan apabila ditekan pada bagian perutnya, telur sudah kelihatan di lubang genital.

Metode pembuahan telur (fertilisasi) digunakan metoda kering artinya proses pembuahan terjadi tanpa adanya media air. Telur dan sperma yang ditampung dalam wadah (basket) tersebut diaduk dengan menggunakan bulu angsa secara merata. Setelah itu, dilakukan pencucian telur dengan air mineral sebanyak dua sampai tiga kali (Gambar 3, 4, 5, dan 6).

Telur yang telah dicampur tersebut segera diinkubasi di akuarium yang telah dilengkapi dengan 


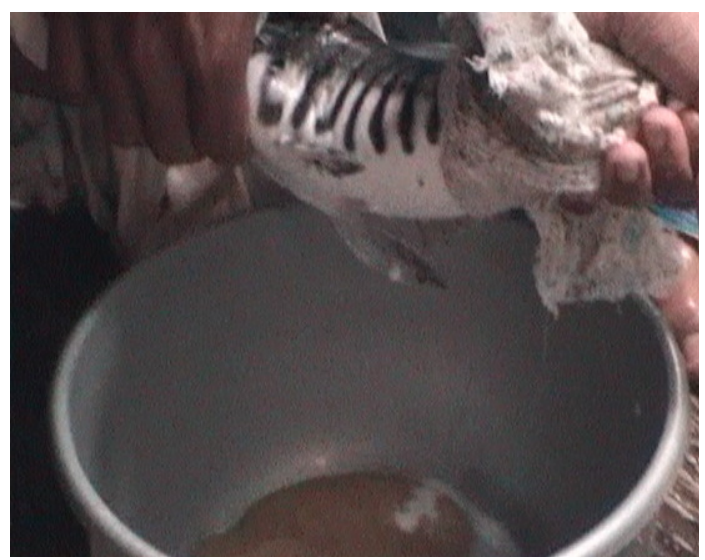

Gambar 3. Pengurutan telur pada induk betina Figure 3. Striping of eggs in the female brood

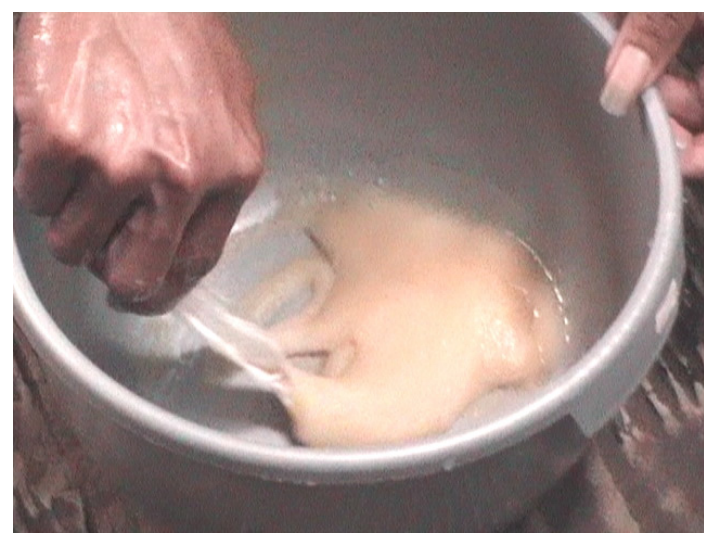

Gambar 5. Pembuahan/pengadukan telur dan sperma secara kering dan manual dengan bantuan bulu angsa

Figure 5. Fertilization/mixing egg and sperm in a dry and manually with the help of goose feathers

aerasi Masing-masing akuarium diisi air setinggi $20 \mathrm{~cm}$ yang berasal dari tandon. Jumlah telur yang dihasilkan setiap satu induk dapat mencapai 300.000 butir dengan daya tetas rata-rata $80 \%$ (Kusrini \& Priyadi, 2013). Telur akan menetas semua dalam waktu 15-19 jam pada suhu berkisar antara $26^{\circ} \mathrm{C}-30^{\circ} \mathrm{C}$. Larva yang telah menetas tetap dibiarkan dalam akuarium sampai kuning telur yang menempel di tubuh habis termakan. Sedangkan keragaan telur yang sedang diinkubasi dalam akuarium dan telur yang telah menetas (larva) dapat dilihat pada Gambar 7.

Berdasarkan pengalaman yang telah dilakukan oleh para breeder maupun pengusaha ikan hias, bahwa ikan hias tiger catfish memijah pada musim penghujan. Sedangkan reproduksi ikan hias tiger catfish di alam atau lingkungan aslinya sampai saat ini belum diketahui, karena survai penelitian untuk mengeskplorasi model pemijahan dan musimnya belum dilakukan. Selain itu, literatur yang mendukung penelitian tersebut untuk ikan hias tiger catfish juga masih sangat terbatas sebagaimana halnya dengan ikan hias yang lain.

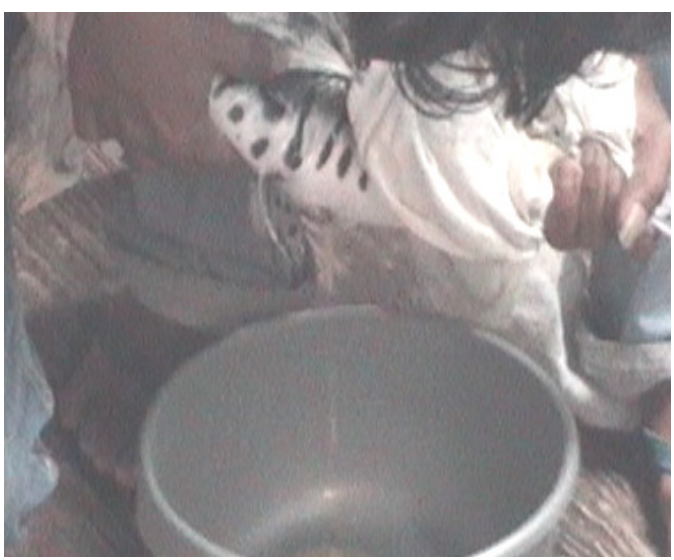

Gambar 4. Pengurutan sperma pada induk jantan Figure 4. Striping sperm in the male brood

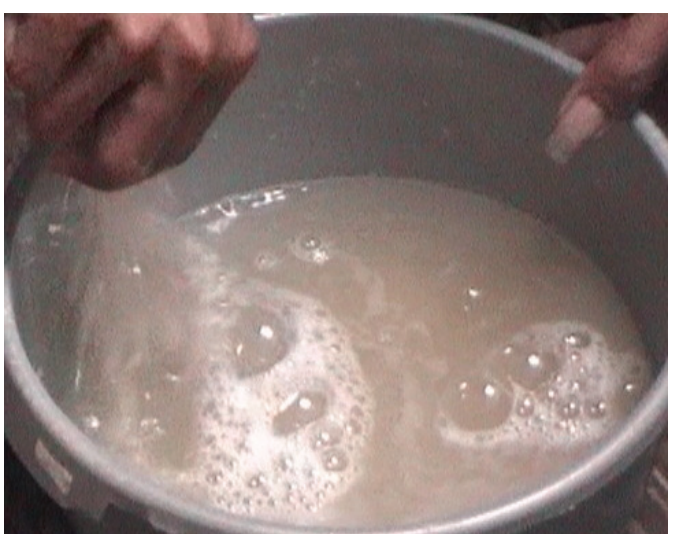

Gambar 6. Pencucian telur menggunakan air mineral

Figure 6. Egg washing using mineral water

Pengembangbiakan yang selama ini dilakukan oleh para breeder, hobiis, dan pengusaha adalah melalui kawin buatan (pemijahan buatan) dengan stimulasi hormone gonadotropin. Pada lingkungan budidaya ikan tiger catfish belum dapat memijah secara alami.

Pada kolam pemeliharaan ikan hias tiger catfish akan terlihat diam di dasar kolam dan akan bergerak agresif apabila terganggu. Hal tersebut ditenggarai ikan tersebut telah matang gonad, secara visual ditandai dengan perut yang lebih buncit dan bulat, apabila diraba terasa lembek. Sedangkan untuk memastikan besarnya perut karena pakan atau telur dengan cara di-striping sedikit sehingga telur (betina) dan sperma (jantan) akan keluar. Keberhasilan pembenihan diawali dari pengelolaan induk yang benar untk dapat matang gonad, sehingga kualitas telur bagus dan akan menghasikan benih-benih yang berkualitas. Teknik pembenihan juga menjadi faktor yang menentukan untuk keberhasilan pembenihan. Teknologi pemijahan buatan dengan menggunakan stimulasi hormon gonadotropin ikan tiger catfish telah dikuasai dan telah berkembang di para breeder ikan hias. 


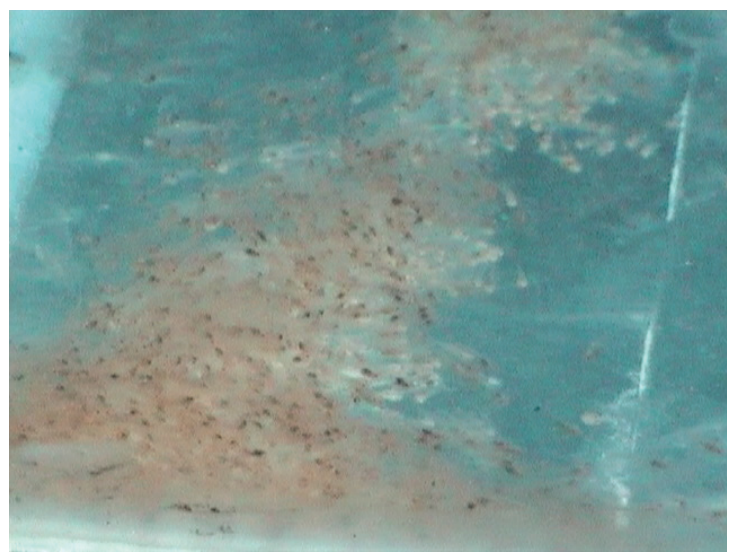

Gambar 7. Keragaan larva yang baru menetas dalam akuarium dengan aerasi

Figure 7. Performance of hatched larvae in aquariums with aeration

Ikan hias tiger catfish (Pseudopltystoma fasciatum) yang merupakan ikan hias berkualitas ekspor ini masih terbatas produksinya di kalangan breeder. Keterbatasan tersebut karena ikan ini belum dapat memijah secara alami sehingga untuk pembudidaya ikan hias umumnya belum menguasai teknologi pemijahan buatan. Permintaan pasar ekspor cukup stabil dengan harga yang relatif stabil pula sehingga sering kurang terpenuhi yang hanya dipasok oleh beberapa breeder dan pengusaha yang telah benar-benar dapat menguasai teknologi pembenihan ikan tersebut secara sempurna.

Prospek usaha ke depan pembenihan ikan tiger catfish ini masih terbuka luas, mengingat sampai saat ini permintaan pasar untuk ukuran benih tidak pernah surut, sedangkan jumlah pembudidayanya masih sedikit. Hal tersebut yang menyebabkan harga ikan tersebut masih tergolong tinggi dan stabil, dengan ukuran rata-rata 1 inchi dengan harga $\mathrm{Rp} 500,-$-Rp $700,-$. Inilah peluang bisnis ikan hias yang menjanjikan dan diharapkan akhirnya banyak breeder ikan hias yang memulai untuk mengembangkan sendiri sehingga dapat memasok pasar internasional menjadi lebih banyak. Dengan demikian pemasukan devisa negara akan meningkat dari sumber ikan hias, sehingga dukungan industrialisasi perikanan dari aspek ikan hias akan semakin lebih nyata.

\section{KESIMPULAN}

Ikan hias tiger catfish (Pseudopltystoma fasciatum) yang merupakan ikan hias berkualitas ekspor ini masih terbatas produksinya di kalangan breeder. Keterbatasan tersebut karena ikan ini belum dapat memijah secara alami sehingga untuk pembudidaya ikan hias umumnya belum menguasai teknologi pemijahan buatan. Pemijahan ikan hias tiger catfish sampai saat ini masih dilakukan secara buatan yaitu dengan stimulasi hormon gonadotropin atau induced spawning. Prospek usaha ke depan pembenihan ikan tiger catfish ini masih terbuka luas, mengingat sampai saat ini permintaan pasar untuk ukuran benih tidak pernah surut, sedangkan jumlah pembudidayanya masih sedikit.

\section{DAFTAR ACUAN}

Gaffar, A.K., \& Muflikhah, N. (1992). Pemijahan buatan dan pemeliharaan larva ikan baung. Prosiding Seminar Hasil Penelitian Perikanan Air Tawar 1991/1992. Balitkanwar. Bogor, hlm. 254-257.

Hardjamulia, A., \& Atmawinata, S. (1990). Teknik hipofisasi beberapa jenis ikan air tawar. Prosiding Lokakarya Nasional Tepatguna bagi Pengembangan Perikanan Budidaya Air Tawar. Bogor, 28-31 Januari 1980.

Hardjamulia, A., Suhenda, N., Ismail, W., \& Priyadi, A. (1992). Teknologi pembenihan ikan jelawat (Leptobarbus hoeveni) secara terkontrol. Seri Pengembengan Hasil Penelitian Perikanan No.PHP/ KAN/PATEK/001/1992.

Kusrini, E., \& Priyadi, A. (2013). Fenotipe generasi pertama dari hasil hibridisasi antara tiger catfish (Pseudoplatystoma fasciatum) dengan redtail catfish (Phractocephalus hemioliopterus). Prosiding Forum Inovasi Teknologi Akuakultur, $10 \mathrm{hlm}$.

Le Bail, P.P., Keith, P., \& Planquette, P. (2000). Pseudoplatystoma tigrinum. http:/www.Pseudoplatystoma. 2 pp.

Sands \& Davis. (2006). Pseudoplatystoma fasciatum. http://www.scotcat.com. Factsheet 36. 18/06/08. 4 pp. 
